\title{
НОВЫЙ МЕТОД НЕЙРОСЕТЕВОЙ СИСТЕМЫ КОНТРОЛЯ УПЛОТНЕНИЯ АСФАЛЬТОБЕТОННЫХ СМЕСЕЙ
}

\section{A NEW METHOD OF NEURAL NETWORK SYSTEM FOR MONITORING OF ASPHALT MIXTURES COMPACTION}

\author{
A. Prokopev \\ Zh. Nabizhanov \\ R. Emelyanov \\ V. Ivanchura
}

Summary. The article considers the task of non-destructive compaction control technology automation of road materials by pavers in real time. A new method is proposed based on the prediction of the compaction coefficient of road materials by an artificial neural network, the input data of which is determined by analyzing the vibration and force state of the sealing working bodies of the compacting equipment. The inputs of the artificial neural network are the type of asphalt mixture (AM), the velocity of the paver, the force in the tamper pusher, the frequency of the tamper, the layer thickness. The theoretical prerequisites of the method of continuous compaction control by pavers are determined.

Keywords: non-destructive technologies, compaction control, artificial neural networks, cyber-physical systems, road construction.
Прокопьев Андрей Петрович К.т.н., доцент, ФГАОУ ВО «Сибирский федеральный университет» prok1@yandex.ru

Набижанов Жасурбек Ильхомович Аспирант, ФГАОУ ВО «Сибирский федеральный университет»

jasur150691@yandex.ru

Емельянов Рюрик Тимофеевич

Д.т.н., профессор, ФГАОУВО «СИбирский федеральный университет» ert-44@yandex.ru

Иванчура Владимир Иванович Д.т.н., профессор, ФГАОУ ВО «СИбирский федеральный университет» ivan43ura@yandex.ru

Аннотация. Рассматривается задача автоматизации неразрушающей технологии контроля уплотнения дорожных материалов укладчиками в режиме реального времени. Предлагается новый метод, основанный на прогнозировании коэффициента уплотнения дорожных материалов искусственной нейронной сетью, входные данные которой определяются в результате анализа вибрационного и силового состояния уплотняющих рабочих органов уплотняющего оборудования. Входами искусственной нейронной сети являются тип асфальтобетонной смеси (АБС), скорость движения асфальтоукладчика, усилие в толкателе трамбующего бруса, частота трамбующего бруса, толщина слоя. Определены теоретические предпосылки метода непрерывного контроля уплотнения для асфальтоукладчиков.

Ключевые слова: неразрушающие технологии, контроль уплотнения, искусственные нейронные сети, киберфизические системы, дорожное строительство.

рых происходит бурное развитие своих теорий: умные дома и умные города, умные производства и умные сети (smart grids), интернет вещей, интеллектуальные встроенные системы и т.д.» [5].

Примером появления прикладной CPS является научное направление «Киберфизические строительные системы» (профессор Волков А.А.) [6], получившее научное основание и развитие в отрасли промышленного и гражданского строительства. Примерами киберфизических систем в дорожно-строительной отрасли, проекты и выпускаемые заводами комплекты приборов для вибрационных катков, являются: нейросетевая система автоматического управления (проект) [7], си- 
стемы непрерывного контроля уплотнения (Continuous Compaction Control, (CC), интеллектуального уплотнения (фирменные комплекты приборов: MOBA; Trimble; TOPCON; Volvo; Sakai; HAMM; CAT; BOMAG; Dynapac) [8, 9]. С учетом государственных планов развития транспортной инфраструктуры в РФ, реализации национальных проектов связанных с строительством автомобильных дорог, совершенствование технологических процессов объектов CPS - асфальтоукладчиков, вибрационных катков, является актуальным направлением науки и технологий [10-14].

Учитывая значительные отраслевые особенности дорожного строительства, научные достижения за период существования CPS, можно сделать прогноз о перспективности развития научного направления по теме «Киберфизические дорожно-строительные системы» (Cyber-physical road construction systems).

\section{Обоснование мето а КОНтроля уп^отнения $\triangle \wedge$ У УКАаАчИкОв}

Из 100\% дефектов и разрушений асфальтобетонных покрытий в мире 50\% возникают по причинам недостаточного и неоднородного уплотнения АБС [15]. Уплотнение представляет собой процесс увеличения плотности дорожно-строительного материала за счет приложения внешних сил уплотнителем. Следовательно, за счет оптимального уплотнения АБС в первую очередь укладчиками и, во вторую - дорожными катками, можно уменьшить до 50\% недостатков дорожных покрытий автомобильных дорог.

Одним из больших недостатков дорожного строительства, влияющим на качество, производительность и экономическую эффективность, является не соответствующий современным требованиям контроль качества уплотнения АБС. Известные методы и средства контроля [7-15] для вибрационных катков, базируются на расчете показателей уплотнения по результатам спектрального анализа (преобразование Фурье) информационных сигналов акселерометров, установленных на вибрационных вальцах катка. В работах [7-15] получены зависимости ускорения вибрационного вальца от числа проходов катка, от свойств асфальтобетонных смесей.

Исследования $[13,14]$, посвященные эффективности применения метода интеллектуального уплотнения (Intelligent Compaction, IC) и CСС на вибрационных катках, показали, что существующие показатели (CCV, CMV, RMV, Evib и др.) обладают значительной погрешностью, и не позволяют корректно судить об эффективности и качестве процесса укатки [14]. Очевидно, это обусловлено тем, что существующие показатели уплотне- ния не учитывают переменные, оказывающие влияние на эффективность уплотнения. Таким образом, разработка метода автоматизированного неразрушающего непрерывного контроля качества уплотнения дорожных материалов укладчиками и вибрационными катками, является задачей, требующей научного и практического решения [15].

Уплотнение асфальтобетонных смесей в дорожном строительстве выполняют комплекты машин, включающие укладчик, вибрационные катки легкого типа, среднего типа и катки тяжелого типа. Выбор типов и количества катков зависит от значения коэффициента уплотнения Ку после укладчика. С увеличением Ку после укладчика, например, до 0,96-0,98, можно убрать из технологического процесса легкие катки, оставив средние и тяжелые катки с уменьшением количества проходов (4-6 проходов). Следовательно, значительное повышение эффективности дорожного строительства можно получить, применяя неразрушающие технологии для контроля и управления укладчиками, целями которых является получение заданного коэффициента уплотнения АБС, уменьшение типов, количества дорожных катков и числа их проходов. Подтверждением высокой уплотняющей эффективности асфальтоукладчиков являются результаты экспериментальных исследований асфальтоукладчика с современным рабочим органом (трамбующий брус, вибрационная плита, две прессующие планки) фирмы VÖGELE (ФРГ), в процессе которых получены значения стандартной плотности АБС типа А (ГОСТ 9128-2013) при скорости 3 м/мин [16].

Полученные в работах [16-21] научные результаты позволяют предложить концепцию (идею) нового метода автоматизированного непрерывного неразрушающего контроля уплотнения дорожных материалов укладчиками, базирующегося на обработке информационных сигналов датчиков преобразующих рабочие режимы (скорость передвижения, частота вращения эксцентрикового вала трамбующего бруса, усилия в толкателе трамбующего бруса (брусьев), для прогнозирования значения коэффициента уплотнения с использованием искусственных нейронных сетей (ИНС).

Цель работы состоит в разработке нового метода автоматизированного непрерывного неразрушающего контроля уплотнения дорожных материалов с привлечением алгоритмических и программно-технических средств построения имитационных моделей процессов, использованием методов искусственного интеллекта, позволяющих улучшить автоматизацию приборов контроля уплотнения, прогнозировать коэффициент уплотнения дорожных материалов, увеличить производительность дорожно-строительных работ, снизить стоимость строительства автомобильных дорог. 


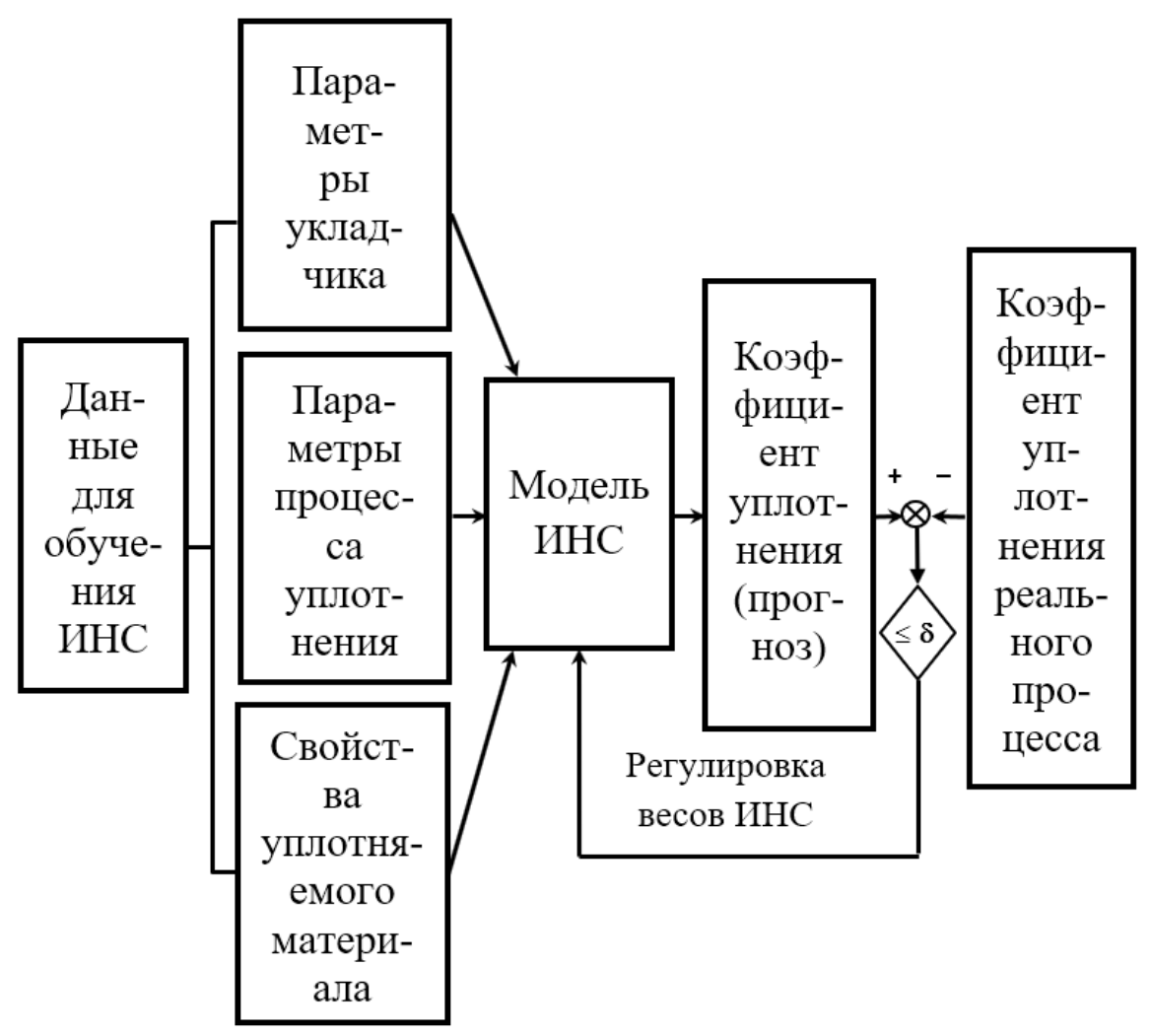

Рис. 1. Функциональная схема обучения модели искусственной нейронной сети

Метод базируется на методах искусственного интеллекта. Спрогнозированное системой контроля значение коэффициента уплотнения позволяет машинисту укладчика скорректировать режимные параметры, автоматически отправить радиосигнал работающим за укладчиком вибрационным каткам для настройки оптимальных режимов их работы. Использование на укладчиках системы непрерывного контроля уплотнения, с учетом применяемых современных САУ, управляющих заполнением шнековой камеры, нивелированием, глобальной навигацией, документированием результатов уплотнения и измерением температуры, значительно повышает уровень автоматизации и доводит машину до соответствия понятию «умный укладчик» (smart paver). В доступных открытых источниках информации отсутствует аналогичные или подобные научные и технические решения.

Киберфизическая дорожно-строительная система включает машины - асфальтоукладчики, дорожные катки среднего и тяжелого типа, датчики и информационные системы машин, которые информационно взаимодействуют между собой используя стандартные интернет-протоколы для прогнозирования коэффициента уплотнения и адаптации к изменениям характеристик АБС и окружающей среды на всех этапах строительства дорожных покрытий автомобильных дорог.

\section{Результаты и обсужление}

Предлагаемый метод реализуется функциональной структурой, включающей датчики, преобразующие скорость передвижения укладчика (тахогенератор), частоту вращения эксцентрикового вала трамбующего бруса (тахогенератор), усилия в толкателе трамбующего бруса (тензодатчики), толщины уплотняемого слоя (ультразвуковой бесконтактный), программируемый логический контроллер с внедренной обученной ИНС. Выходной информационный сигнал системы автоматического контроля (САК) уплотнения для укладчиков соответствует значению коэффициенту уплотнения АБС Ку.

Синтез ИНС состоит из трех этапов обработки - процесса обучения, тестирования и проверки. Предварительные исследования, анализ результатов и оценка потребной производительности вычислительных средств позволяют сделать Вывод, что многослойная нейронная сеть дает лучший прирост эффективности обработки информации о коэффициенте уплотнения асфальтобетонной смеси. Такая сеть показала хорошие результаты по сравнению с такими сетями, как обобщенная регрессионная сеть, однослойный Персептрон, сеть Эльмана, каскадная сеть с прямым распространением сигнала. Многослойная нейронная сеть состоит из нейронов, ко- 
торые расположены на разных уровнях. В сети присутствует входной и выходной слой, а также минимум один скрытый слой. Первый слой отвечает за вектор входных данных сети - параметры машины, процесса и асфальтобетонной смеси. Второй слой - скрытый слой сети с десятью искусственными нейронами, предназначен для увеличения нелинейности и представления данных для обобщения функции. Третий слой - выходной слой сети, выполняет прогнозирование Ку АБС.

Данные, полученные в полевых условиях, были использованы для разработки модели многослойной нейронной сети. Процесс обучения ИНС показан на рис. 1.

Предполагается наличие базы обучающих примеров для сети. Каждый образец обучающей выборки, собранный по результатам лабораторных и полевых испытаний, подается на входной слой сети. Затем обрабатывается внутри структуры ИНС. Полученное в режиме реального времени значение $K y$, сравнивается с соответствующими данными из подготовленных образцов. Далее рассчитывается ошибка обучения ИНС $\delta$ на основе метода средней квадратичной ошибки. При превышении заданного значения ошибки, выполняется изменение весовых коэффициентов связей между слоями ИНС. Изменение весовых коэффициентов происходит на основе алгоритма метода обратного распространения ошибки, который хорошо подходит к структуре сети. В каждой итерации весовые коэффициенты нейронов изменяются с использованием новых данных из обучающей выборки. Веса изменяются пока ошибка обучения сети не достигнет значения $\leq 1 \%$.

Для проектирования ИНС требуются большие данные (англ. big data) входной информации. Особенности реальных условий дорожного строительства, где используются горячие асфальтобетонные смеси, создают значительные проблемы для получения необходимых информационных сигналов процесса уплотнения. На предварительном этапе исследовательского проекта обучающие выборки построены по результатам экспериментальных исследований асфальтоукладчика с рабочим органом, состоящим из двух трамбующих брусьев и выглаживающей плиты, в реальных условиях строительства автомобильной дороги «Николаев Кировоград» $[17,18]$. По эти данным сделаны выводы о наличии функциональной зависимости коэффициента уплотнения АБС от максимального усилия в толкателях трамбующего бруса. Возрастание сопротивления смеси уплотнению происходит постепенно и достигает максимальных значений после 4-5 силовых воздействий на смесь трамбующим брусом. Экспериментальные исследования проводились при скоростях движения ас- фальтоукладчика 1,6, 3,2, 4,8 м/мин, частотах вращения эксцентрикового вала привода трамбующих брусьев изменялась от 1100 мин-1 до 1700 мин-1. Значения максимальных усилий в толкателях определялись по сигналам тензодатчиков наклеенных на металлоконструкцию толкателей трамбующих брусьев. Величина усилий в толкателях трамбующих брусьев в процессе уплотнения асфальтобетонной смеси типа Б (ГОСТ 9128-2013), при толщине слоя покрытия 0,05 м, изменялась от 10 кН (при коэффициенте уплотнения $K \mathrm{y}=0,92)$ до 23 кН $(K y=0,99)$.

В рамках пилотного проектирования нейросетевой системы непрерывного контроля уплотнения дорожных материалов укладчиками в качестве исходных данных использованы результаты теоретических и экспериментальных исследований уплотняющих рабочих органов асфальтоукладчиков на стенде-укладчике, оборудованном тензометри-ческой аппаратурой, при уплотнении аналога песчаной асфальтобетонной смеси типа «Д», проведенных в НПО «ВНИИстройдормаш» $[19,20]$, а также результаты экспериментальных исследований асфальтоукладчиков (модели Титан-410С, Супер-1700, SSF-5), в реальных условиях эксплуатации, при укладке АБС типа А, Б, В, Г (ГОСТ 9128-2013), выполненных учеными СоюзДорНИИ [21]. По экспериментальным данным, опубликованным в работе [21], получены математические модели в форме регрессионных уравнений зависимости коэффициента уплотнения Ку от частоты $f$ в Гц (от 3 до 27,5 Гц) трамбующего бруса для разных типов (А, Б, В, Г) асфальтобетонной смеси, при различных скоростях $V p$ (от 1 до 5 м/мин) передвижения укладчиков. Достоверность аппроксимации регрессионных уравнений $R 2$ по шкале Чеддока-Снедекора высокая $(0,8-0,9)$ и сильная $(0,91-0,99)$.

Подготовленные данные являются исходными наборами больших данных необходимых для обучения ИНС системы непрерывного контроля уплотнения дорожных материалов укладчиками.

\section{Выво $\triangle \mathrm{b}$}

В работе предложена идея (концепция) автоматизации непрерывного неразрушающего контроля уплотнения асфальтобетонных смесей укладчиками на базе методов искусственного интеллекта как объекта киберфизической дорожно-строительной системы. Получена функциональная схема обучения модели искусственной нейронной сети. Обоснованы наборы больших данных для обучения искусственной нейронной сети САКУ для укладчиков. Обоснованность метода подтверждается необходимым объемом теоретических и экспериментальных исследований российских ученых на испытательных полигонах и реальных условиях эксплуатации асфальтоукладчиков. 


\section{ЛИТЕРАТУРА}

1. Fradkov A. L. Cybernetical physics: from control of chaos to quantum control. (Berlin, Germany: Springer), 2007, XII, $236 \mathrm{p}$.

2. Fradkov A. L. Horizons of cybernetical physics. Phil. Trans. R. Soc. A 375, 2017, 20160223.

3. Anderl R., Eigner M., Sendler U. and Stark R. Smart Engineering — Interdisziplinäre Produktentstehung. Acatech Diskus. Springer, 2012,58 p.

4. Serpanos D. and Wolf M. Internet-of-Things (loT) Systems. Architectures, Algorithms, Methodologies. Springer Cham, 2018, 95 p.

5. Фрадков А. Л. Киберфизические системы: идеи и перспективы. ХІІІ Всероссийское совещание по проблемам управления (ВСПУ-2019) Институт проблем управления им. Трапезникова Москва; Россия, 2019.

6. Волков А. А. Кибернетика строительных систем. Киберфизические строительные системы. Промышленное и гражданское строительство. № 9. 2017. C. 4-7.

7. Pistrol J., Villwock S., Völkel W., Kopf F. and Adam D. Continuous Compaction Control (CCC) with Oscillating Rollers. Procedia Engineering, 143, 20165 , pp 14-21.

8. Hu W., Shu X., Huang B. and Woods M. Field investigation of intelligent compaction for hot mix asphalt resurfacing. Frontiers of Structural and Civil Engineering, 11(1), 2017, pp 47-55.

9. Barman M., Nazari M., Imran S. A., Commuri S., Zaman M., Beainy F. and Singh D. Quality Control of Subgrade Soil Using Intelligent Compaction. Innovative Infrastructure Solutions, 1(1), 2016, pp 23.

10. Liu D.H., Li Z. L. and Lian Z. H. Compaction quality assessment of earth-rock dam materials using roller integrated compaction monitoring technology. Autom. Constr., 44, 2014, pp 234-246.

11. Kenneally B., Musimbi 0. M. and Wang J. Finite element analysis of vibratory roller response on layered soil systems. Comput. Geotech., 67, $2015, \mathrm{pp} 73-82$.

12. Li J., Zhang Z. and Xu H. Dynamic characteristics of the vibratory roller test-bed vibration isolation system: simulation and experiment. J. Terramechanics, 56, 2014, pp 139-156.

13. Xu Q. and Chang G. K. Adaptive quality control and acceptance of pavement material density for intelligent road construction. Automat. Constr., 62, 2016, pp 78-88.

14. Zhu X., Bai S., Xue G., Yang J., Cai Y., Hu W., Jia X. and Huang B. Assessment of compaction quality of multi-layer pavement structure based on intelligent compaction technology. Constr. Build. Mater., 161, 2018, pp 316-329.

15. Захаренко А.В., Пермяков В. Б., Молокова Л. В. Дорожные катки: теория, расчет, применение. СПб.: Издательство «Лань», 2018.328 с.

16. Кустарев Г.В., Павлов С. А., Ушков А. В. Высокоэффективные комплексы для скоростного строительства асфальтобетонных покрытий: монография. М.: МАДИ, 2019. 140 C.

17. Прокопьев А.П., Емельянов Р. Т. Автоматизация процесса уплотнения асфальтоукладчика. Изв. высш. учеб. завед. строительство. № 7 (547). 2004. C. $82-84$.

18. Prokopev A.P., Nabizhanov Zh.I., Emelyanov R. T., Ivanchura V. I. Concept of a new method for continuous non-destructive control of asphalt road pavements compaction. Journal of Physics: Conference Series, 1515, 2020, 052054.

19. Кизряков А.Н., Кабанов В. В., Фруктов П. А. Исследование уплотняющих рабочих органов асфальтоукладчиков. Труды ВНИИСтройдормаш. Вып. 102. 1985. С. 3-7.

20. Кизряков А.Н., Кабанов В. В., Фруктов П.А. Определение параметров виброуплотняющих органов асфальтоукладчиков. Труды ВНИИстройдормаш. Вып. 107. 1986. С. 63-68.

21. Марышев Б.С., Слепая Б. М., Питецкий Ю. Н., Скрыльник А. П., Островский Э. Б., Либерман М. А., Ксоврели П. И. Уплотнение асфальтобетонных смесей асфальтоукладчиками. Автомобильные дороги. № 11. 1979. С. 11-12.

(с Прокопьев Андрей Петрович ( prok1@yandex.ru ), Набижанов Жасурбек Ильхомович ( jasur150691@yandex.ru ), Емельянов Рюрик Тимофеевич ( ert-44@yandex.ru),Иванчура Владимир Иванович ( ivan43ura@yandex.ru ). 